\title{
Agentes Pedagógicos Emocionais atuando em um Ambiente Virtual de Aprendizagem
}

\author{
Rejane Frozza ${ }^{1,2}$ (frozza@unisc.br) \\ Andréa Aparecida Konzen da Silva (andrea@unisc.br) \\ Jacques Nelson Corleta Schreiber ${ }^{1,2}$ (jacques@unisc.br) \\ Beatriz Lux² (lux@unisc.br) \\ Kurt Werner Molz ${ }^{2}$ (kurt@unisc.br) \\ Liane Mahlmann Kipper ${ }^{1}$ (liane@unisc.br) \\ Mirceia Pereira Borin ${ }^{1}$ (ceiaborin@ yahoo.com.br) \\ Amanda Brum de Carvalho ${ }^{2}$ (abrum.work@gmail.com) \\ Jorlei Luis Baierle² (jorleib@bol.com.br) \\ Lariane Sampaio ${ }^{2}$ (lary-sampaio@hotmail.com) \\ Universidade de Santa Cruz do Sul - UNISC \\ ${ }^{1}$ Programa de Pós-Graduação em Sistemas e Processos Industriais - PPGSPI \\ ${ }^{2}$ Departamento de Informática \\ Av. Independência, 2293- CEP 96640-000 - Santa Cruz do Sul - RS
}

Resumo. A aprendizagem é uma das atividades mais ricas desenvolvidas pelo homem. Assim, a utilização de novas tecnologias neste processo, como a computação afetiva, é promissora. Na computação afetiva, encontram-se os conhecimentos da psicologia e da ciência cognitiva, sendo possível estudar como os sistemas computacionais podem detectar, classificar e responder às emoções humanas. Este artigo apresenta o desenvolvimento e a atuação de dois agentes pedagógicos animados, expressando emoções (tutor e companheiro), integrados em um ambiente virtual de aprendizagem, a fim de interagir com estudantes. $O$ agente tutor Dóris tem o papel semelhante a de um professor, identificando as características de aprendizagem do estudante. $O$ agente companheiro Dimi atua juntamente com o estudante na realização de atividades propostas pelo ambiente virtual, fornecendo dicas e desafios.

Palavras-Chaves: agentes pedagógicos emocionais, ambiente virtual de aprendizagem, estilos cognitivos, modelagem de emoções em agentes pedagógicos.

Title. Emotional Pedagogical agents acting in a Virtual Learning Environment

Abstract. Learning process is an important activity for the humans. Thus, the use of new technologies in this process, such as affective computing, is promising. In affective computing, the areas as psychology and cognitive science are closed. It is possible to study how computer systems can detect, classify and respond to human emotions. This paper presents the development of two animated pedagogical agents, expressing emotions (tutor and companion), embedded in a virtual learning environment, to interact with students. Doris tutor agent has a role like a teacher, identifying the characteristics of student learning. Dimi companion agent acts with the student to conduct activities proposed by the virtual environment, providing tips and challenges.

Keywords: emotional pedagogical agents, virtual learning environment, cognitive styles, modeling emotions in pedagogical agents. 


\section{Introdução}

De acordo com (Azevedo; Tavares, 2001), a aprendizagem é uma das atividades mais ricas desenvolvida pelo homem, devido à assimilação de novos conhecimentos. Geralmente, o local onde este aprendizado ocorre é na sala de aula, verificando assim, a importância do papel do professor. Na visão de (Silva; Heck, 2008) experiências agradáveis, em relação à utilização de recursos tecnológicos nas atividades de ensino, têm sido relatadas por estudantes e professores. Na opinião dos professores, o computador permite a simulação de situações, que, com o quadro e o giz, seria difícil de realizar.

Um dos recursos utilizados para que isto ocorra são os ambientes virtuais de aprendizagem e, entre eles, mais especificamente os Sistemas Tutores Inteligentes (STI), que são softwares utilizados para dar suporte às atividades de aprendizado dos estudantes, com propósitos educacionais que incorporam técnicas da Inteligência Artificial, como o uso de agentes pedagógicos (Gavidia; Andrade, 2003).

Um AVA (Ambiente Virtual de Aprendizagem) é constituído por uma infra-estrutura tecnológica (interface gráfica, comunicação síncrona/assíncrona e outras funcionalidades) e por todas as relações (afetivas, cognitivas, simbólicas, entre outras) estabelecidas pelos sujeitos participantes, tendo como foco principal a aprendizagem (Behar, el al., 2007). Assim, um AVA vai além da ideia de um conjunto de páginas educacionais na Web, mas que é um ambiente virtual de aprendizagem onde o espaço social é constituído de interações cognitivo-sociais sobre ou em torno de um objeto de conhecimento, que pode ser considerado como o assunto ou tema de estudo.

Em relação à emoção, segundo (Berch, 2001), esta surge a partir das experiências vividas pelo ser humano e dos objetos de seu pensamento, e pode ser caracterizada por reações expressivas, como sorrisos, cenho franzido, dentes trincados; por reações fisiológicas, como aumento dos batimentos cardíacos, produção de lágrimas, calores e vermelhidão no rosto; por comportamentos instrumentais, como correr, juntar as mãos; por comportamentos instrumentais situacionais, como digitar com força desmesurada uma tecla, gritar um impropério qualquer; por cognições, como pensamento de injustiça para si ou para outros, sensação de impotência frente a problemas; e por sentimentos que integram os fenômenos fisiológicos e cognitivos, como a tristeza (sensação de um aperto no peito, lágrimas nos olhos e a lembrança do evento que gerou tais sensações).

Desta forma, o objetivo desta pesquisa é proporcionar aos estudantes um ambiente educacional apoiado por agentes pedagógicos emocionais, que possa contribuir para o processo de ensino-aprendizagem, focando no processo de interação entre estudantes e ambiente.

O artigo está organizado nas seguintes seções: a seção 2 aborda o ambiente virtual de aprendizagem desenvolvido e os estilos cognitivos e as táticas de ensino disponíveis no ambiente; a seção 3 aborda algumas características da área de computação afetiva; na seção 4 descrevem-se os agentes tutor e companheiro e como as emoções foram definidas; e a seção 5 apresenta as conclusões.

\section{Ambiente virtual de aprendizagem baseado em estilos cognitivos}

Os estilos cognitivos e de aprendizagem dizem respeito à forma e não ao conteúdo do que se pensa, sabe, percebe, lembra, aprende ou decide. Entretanto, os estilos de aprendizagem estão mais relacionados à forma como o estudante processa a informação na resolução de problemas; já no estilo cognitivo se sobressai a maneira como os 
estudantes interagem em condições de aprendizagem, abrangendo aspectos cognitivos, afetivos, físicos e ambientais, que favorecem o processamento de informações.

Uma das principais características do estilo cognitivo de uma pessoa é a forma de aproximação que esta realiza do conteúdo a ser aprendido, denominada independência/dependência de campo. De acordo com (Chou; Chan; Lin, 2003), essa é uma dimensão que se refere a uma tendência para aproximar-se do ambiente de forma analítica em oposição à global. $\mathrm{O}$ estilo independente de campo tem como característica a análise específica, com criação de uma síntese própria, aprendizagem individual e facilitada quando o conteúdo é apresentado em série, com pistas internas para ajudar o estudante a resolver os problemas. Já o estilo dependente de campo apresenta dificuldades em separar a parte do todo, logo, o estudante realiza sínteses genéricas e superficiais (globais), percepção geral do campo aguçada e aprendizagem cooperativa.

Nos estudos sobre estilos cognitivos utiliza-se um Inventário de Estilo Cognitivo e o Group Embedded Figures Test - GEFT. A fim de manter algumas das características medidas no Inventário e no GEFT, utilizou-se o Teste Ross de Processos Cognitivos, visto que este está padronizado para a população brasileira e tem como um dos objetivos principais a avaliação da performance individual dos estudantes quanto aos processos de pensamento (Ross \& Ross, 1976). O Teste Ross foi concebido para medir 3 habilidades gerais (Análise, Síntese e Avaliação), sendo 8 os subtestes (Analogias, Raciocínio Dedutivo, Premissas Ausentes, Relações Abstratas, Síntese Seqüencial, Estratégias de Questionamento, Análise de Informações Relevantes e Irrelevantes, e Análise de Atributos).

A identificação dos estilos cognitivos abordados no ambiente educacional desenvolvido foi realizada por meio de um estudo empírico com estudantes da graduação, com a aplicação do Teste de Ross. Os objetivos deste estudo foram: identificar características de raciocínio e estratégias de aprendizagem; comparar as características identificadas na amostra com uma das dimensões que caracteriza o estilo cognitivo (dependência/independência de campo) para gerar as variáveis referentes ao estilo cognitivo do estudante, necessárias para a modelagem do sistema tutor inteligente.

Para a realização do estudo foram convidados a participar estudantes universitários de diferentes semestres, com idades entre 18 e 40 anos, de ambos os sexos, compondo uma amostra intencional de 193 universitários (114 dos cursos de bacharelado e licenciatura em Computação e 79 do curso de Psicologia). Destaca-se que foi escolhida uma amostra de estudantes universitários porque o sistema tutor inteligente poderá ser aplicado tanto a nível educacional médio como superior.

A partir da análise dos resultados desse estudo empírico, tomando-se como ponto de referência as médias em cada um dos subtestes do Teste de Ross, foram geradas duas categorias de estilo cognitivo principais, baseadas nas características da dimensão dependência/independência de campo, conforme a tabela 1 .

As táticas de ensino desenvolvidas, segundo as características dos estilos cognitivos, e utilizadas na apresentação do material instrucional, são apresentadas na tabela 2. O estilo A e o estilo B diferem na ordem em que os subtestes (Raciocínio Dedutivo, Análise de Informação Relevante e Irrelevante, Premissas Ausentes, Análise de Atributos) são analisados.

O ambiente virtual de aprendizagem desenvolvido é um sistema tutor inteligente, com a atuação dos agentes pedagógicos tutor e companheiro, baseado em estilos cognitivos para adaptação às características de aprendizagem dos estudantes. 
Tabela 1 - Categorias de estilos cognitivos

\begin{tabular}{|c|c|}
\hline Categoria A - Independente de campo & Categoria B - Dependente de campo \\
\hline aproximação analítica & aproximação global \\
\hline motivação interna & percepção global \\
\hline aprendizagem individual & aprendizagem em grupo \\
\hline autodefinição dos objetivos & determinação externa dos objetivos \\
\hline
\end{tabular}

Tabela 2 - Relação entre estilos cognitivos e táticas de ensino

\begin{tabular}{|c|c|c|}
\hline \multirow[b]{2}{*}{ Teste de Ross } & Estilo A & Estilo B \\
\hline & $\begin{array}{l}\text { 1- Raciocínio Dedutivo } \\
\text { 2- Premissas Ausentes } \\
\text { 3- Análise de Atributos }\end{array}$ & $\begin{array}{l}\text { 1- Análise de Informação } \\
\text { Relevante e Irrelevante } \\
\text { 2- Análise de Atributos } \\
\text { 3- Premissas Ausentes }\end{array}$ \\
\hline & Verbal & Imagética \\
\hline $\begin{array}{c}\text { Agrupamento } \\
\text { das táticas }\end{array}$ & \begin{tabular}{|l}
-exemplos com textos \\
-exemplos com som e textos \\
-frases a serem organizadas \\
-selecionar colunas (texto) \\
-verdadeiro/falso \\
-escolha múltipla \\
-texto com perguntas \\
-preencher lacunas (texto)
\end{tabular} & $\begin{array}{l}\text {-exemplos com figuras } \\
\text {-exemplos com figuras e som } \\
\text {-figuras a serem organizadas } \\
\text {-relacionar colunas (figuras) } \\
\text {-preencher lacunas (figuras) } \\
\text {-textos com trechos destacados } \\
\text {-textos com figuras relacionadas } \\
\text {-texto com som }\end{array}$ \\
\hline
\end{tabular}

Uma versão simplificada do teste de Ross é utilizada quando o estudante faz o primeiro acesso ao sistema educacional, a fim de que o sistema tenha um ponto de partida para a adaptação da forma de apresentação do conteúdo, segundo um dos estilos inicialmente definidos - verbal (Estilo A - independente de campo) ou imagético (Estilo B dependente de campo). Este estilo pode sofrer alterações à medida que o estudante interage com o sistema. A escolha de apenas dois estilos iniciais deve-se ao uso das dimensões identificadas no estudo empírico, dependente e independente de campo.

\section{Computação afetiva}

A computação afetiva é uma subárea da inteligência artificial, que reúne conhecimentos da psicologia e da ciência cognitiva. Através desta é possível estudar como os sistemas computacionais podem detectar, classificar e responder às emoções humanas.

Rosalind Picard (Picard, 1997) afirma que a "computação afetiva é a computação que está relacionada com, que surge de ou deliberadamente influencia emoções". Para isto ocorrer, os computadores devem ser capazes de "ler" as emoções, ou seja, deduzir o estado emocional com base no comportamento observável.

A computação afetiva possui duas divisões básicas de pesquisa, onde, uma delas estuda a interação humano-computador, ou seja, o mecanismo para o reconhecimento das emoções humanas ou a expressão destas por máquinas; e outra estuda a simulação de emoções em máquinas, buscando torná-las mais reais possíveis.

Os trabalhos de (Jaques; Lehmann, 2008) apontam que o sistema deve reconhecer as emoções do estudante, a fim de se adaptar a sua afetividade. Exemplificando, pode-se dizer que, se o estudante se frustrar no desenvolvimento de alguma tarefa, possivelmente ele irá desistir. 
De acordo com (Berch, 2001), a emoção na computação implica em diferentes aspectos nos sistemas, desde o controle até a personalização de interfaces, da simulação de sistemas com emoções à representação de emoções, do estudo das emoções através de sistemas até pesquisas que envolvem emoções nas interações Homem-Máquina, que nos leva ao conceito de agentes emocionais, ou seja, agentes inteligentes que possuem características de afetividade, sem perder a capacidade de realizar raciocínios puramente intelectuais. Características estas que levam ao conceito de sistemas afetivos, que são sistemas desenvolvidos com algumas das capacidades de reconhecer, expressar, possuir ou desenvolver emoções.

Assim, vários sistemas educacionais têm buscado considerar as emoções do estudante através de inferência, bem como responder emocionalmente a ele, através da geração de emoção. A avaliação do processo de ensino e aprendizagem deve ir além dos objetivos relacionados ao conteúdo.

Um dos modelos mais utilizados na Inteligência Artificial, por ser facilmente instanciado em computadores através de uma base de conhecimento, é conhecido como OCC, que foi desenvolvido em 1988 pelos autores que dão nome ao modelo (Andrew Ortony, Gerald Clore e Allen Collins) que, segundo (Lino; Tedesco; Rousy, 2006), se baseia na estrutura cognitiva das emoções. Este modelo é composto por 22 emoções que descrevem os processos cognitivos de avaliação que disparam uma emoção. As emoções são divididas em três categorias, dependendo do estímulo: Eventos (objetivos ou consequiências; por exemplo, medo), Agentes (o próprio ou outros; por exemplo, orgulho), Objetos (podem ser apreciados ou não; por exemplo, gostar).

Por este motivo, busca-se representar os agentes pedagógicos como personagens animados, capazes de representar diferentes tipos de emoções. Mas é necessário identificar qual é o comportamento mais adequado para promover uma ação positiva no estudante, a fim de proporcionar uma melhor aprendizagem.

\section{Agentes pedagógicos emocionais tutor e companheiro}

Os agentes pedagógicos utilizados no sistema tutor inteligente são os agentes tutor e companheiro. $\mathrm{O}$ agente tutor tem o papel semelhante a de um professor, identificando as características de aprendizagem do estudante. $\mathrm{O}$ agente companheiro atua juntamente com o estudante na realização das atividades propostas pelo ambiente, fornecendo dicas e desafios.

Os agentes possuem um módulo de tomada de decisão, que é responsável por analisar as características do estudante e relacioná-las com as táticas de ensino a serem utilizadas para a apresentação do material instrucional. Tal módulo tem sua ativação por meio de regras de produção, na qual as condições são as características dos estudantes e as ações são as táticas de ensino.

\subsection{Modelagem das Emoções}

Agregou-se o modelo de emoções como metodologia para melhorar o processo de interação individualizada do ambiente desenvolvido com os estudantes. Devido à importância das emoções na aprendizagem, e também por estudos sobre as emoções, escolheu-se, inicialmente, o desenvolvimento de sete emoções para modelagem no agente tutor Dóris e duas emoções (alegria e tristeza) para modelagem no agente companheiro Dimi, conforme a tabela 3. Estas emoções foram escolhidas com base do modelo OCC, na teoria do livro "O Corpo Fala" (Tompakow, 2008) e no autor 
(Ekmamm, 1999), pois as emoções não são apenas representadas pela face, mas também pelo corpo.

Tabela 3 - Características das expressões para os agentes

\begin{tabular}{|c|c|}
\hline Expressão & Descrição \\
\hline Alegria & $\begin{array}{l}\text { Sobrancelhas relaxadas; boca aberta e os cantos da boca voltados para } \\
\text { cima; olhos brilhantes. }\end{array}$ \\
\hline Tristeza & $\begin{array}{l}\text { Parte interior das sobrancelhas (perto do nariz) elevada; olhos } \\
\text { ligeiramente fechados; a boca relaxada, com os cantos voltados para } \\
\text { baixo. }\end{array}$ \\
\hline Expectativa & $\begin{array}{l}\text { Olhos atentos para frente; boca (sorriso com lábios fechados); mãos: na } \\
\text { boca ou no queixo; sobrancelhas levantadas (distensão do músculo } \\
\text { orbicular mais contração do frontal). }\end{array}$ \\
\hline Indignação & $\begin{array}{l}\text { As sobrancelhas e pálpebras estão mais juntas e os olhos mais levemente } \\
\text { fechados; o lábio superior eleva-se de modo assimétrico fazendo uma } \\
\text { pequena curva; mãos na cintura. }\end{array}$ \\
\hline Surpresa & $\begin{array}{l}\text { Sobrancelhas elevadas; pálpebras superiores muito abertas e as inferiores } \\
\text { muito relaxadas; a boca fica aberta, descendo o maxilar inferior. }\end{array}$ \\
\hline Atenção & $\begin{array}{l}\text { Cotovelos apoiados na mesa, com uma mão apoiada no rosto e a outra } \\
\text { com os dedos na boca; olhos atentos para frente; sobrancelhas levantadas } \\
\text { (distensão do músculo orbicular mais contração do frontal). }\end{array}$ \\
\hline Dúvida & Olhos elevados; uma mão na cabeça. \\
\hline
\end{tabular}

Fonte: Baseado em EKMANN, P. Basic Emotions, 1999. Disponível em: http://www.paulekmann.com/ pdfs/basic_emotions.pdf; e WEIL, Pierre;TOMPAKOW, R. O corpo fala. 64 edição. Petrópolis: Vozes, 2008. PICARD, R. Affective Computing. Cambridge: MIT Press, 1997.

O modelo OCC contribuiu para a definição do comportamento dos agentes na expressão de cada emoção, dependendo do estímulo recebido pela ação do estudante no ambiente. Muitas expressões são capazes de traduzir emoções e sentimentos sem usar palavras, e a face é considerada o principal elemento das expressões, ou seja, os principais elementos da comunicação humana. Portanto, (Ekman, 1999) salienta que a animação facial exige que se tenha certo conhecimento da anatomia facial, principalmente a estrutura muscular, pois tem o objetivo de representar expressões faciais de maneira que continuem sendo reconhecidas como familiares aos seres humanos.

Kendall e Creary (1995) também afirmam que os movimentos faciais são fortemente influenciados por três áreas, as sobrancelhas, os olhos e a boca.

\subsection{Agente tutor Dóris}

As emoções, apresentadas na tabela 3 (seção 4.1), de alegria, tristeza, expectativa, indignação, surpresa, atenção e dúvida, têm a descrição relacionada da expressão nas feições do agente pedagógico Dóris. Estas emoções são expressas pelo agente no ambiente de interação com o aluno.

A seguir, se apresenta uma das expressões modeladas, a expressão de dúvida, conforme figura 1 .
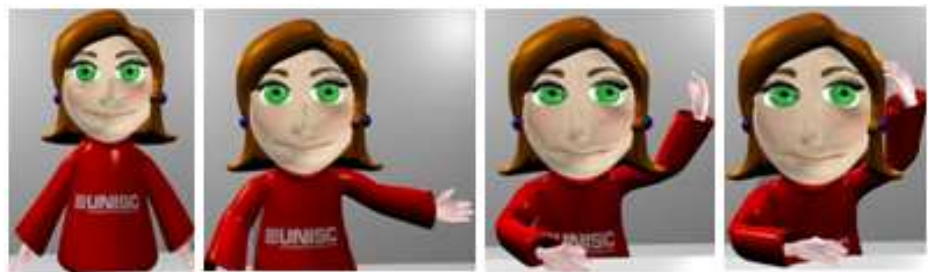

Figura 1 - Etapas da expressão de dúvida do agente modelado para o ambiente virtual de aprendizagem 
A expressão de dúvida é caracterizada principalmente pelos olhos elevados, como pode ser observada na figura 1, a mão na cabeça auxilia na interpretação da emoção. Utilizada em momentos que o usuário possa estar com dúvida na compreensão do conteúdo, como, por exemplo, quando está realizando os exercícios e volta para o conteúdo, figura 2 , ou quando acessa o cadastro de dúvidas.

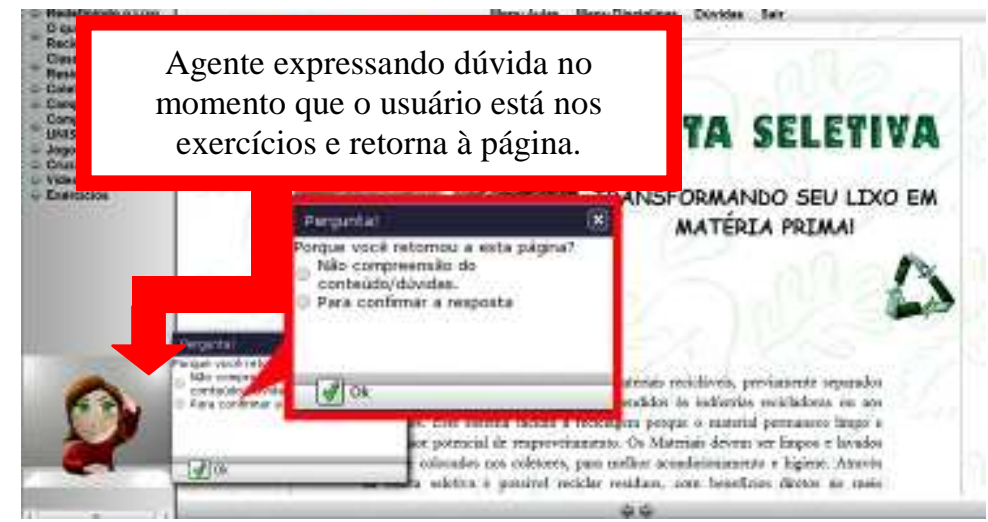

Figura 2 - Exemplo da expressão dúvida no ambiente

A atuação do agente Dóris no ambiente é determinada por um conjunto de regras de produção (formato: SE <condição> ENTÃO <ação>) constituídas de condições/percepções e reações/ações. A idéia é que, ao perceber situações que acontecem no ambiente, o agente reaja com a realização de alguma ação.

Assim, para fazer a modelagem das expressões, iniciou-se pela elaboração de um diagrama de Casos de Uso (Use Cases) que demonstrassem de forma clara o agente Dóris e as expressões exercidas no ambiente virtual de aprendizagem, representado na figura 3. Por exemplo, o caso de uso "Aguardar resposta do usuário em relação à tática de ensino", refere-se à resposta do usuário sobre ele estar gostando ou não da tática utilizada pelo ambiente de aprendizagem.

\subsection{Agente companheiro Dimi}

O agente companheiro é um personagem afetivo que tem a função de acompanhar o estudante em seus estudos e no cumprimento de suas tarefas, procurando mantê-lo motivado a continuá-las, apesar das dificuldades encontradas no decorrer da realização das mesmas (Kammpff, 2005).

De forma geral, um companheiro de aprendizagem nada mais é do que um agente com características humanas que desempenha um papel colaborativo em um ambiente de aprendizagem, sendo considerado um tipo de agente educacional (Chou; Chan; Lin, 2003).

O agente companheiro Dimi tem sua aparência atual em 3D, a fim de atrair a atenção por parte dos estudantes, buscando motivá-los a seguir com suas tarefas durante a aprendizagem. A arquitetura do agente Dimi é formada pelos módulos cognitivo (age através do raciocínio), perceptivo (age por percepção) e reativo (age por impulso). $\mathrm{O}$ módulo cognitivo visa interagir com o estudante, a fim de estimular este a desenvolver suas tarefas. Neste módulo, ocorre a interação com a base de conhecimento, para a definição das ações do agente, tais como a seleção de mensagens que o agente irá emitir. No módulo perceptivo ocorre a coleta e o armazenamento de informações de fatos que ocorrerão durante a interação, por exemplo, o agente monitora as dificuldades do estudante na realização das atividades e dúvidas encontradas. O módulo reativo é responsável por executar as ações definidas pelo módulo cognitivo. 


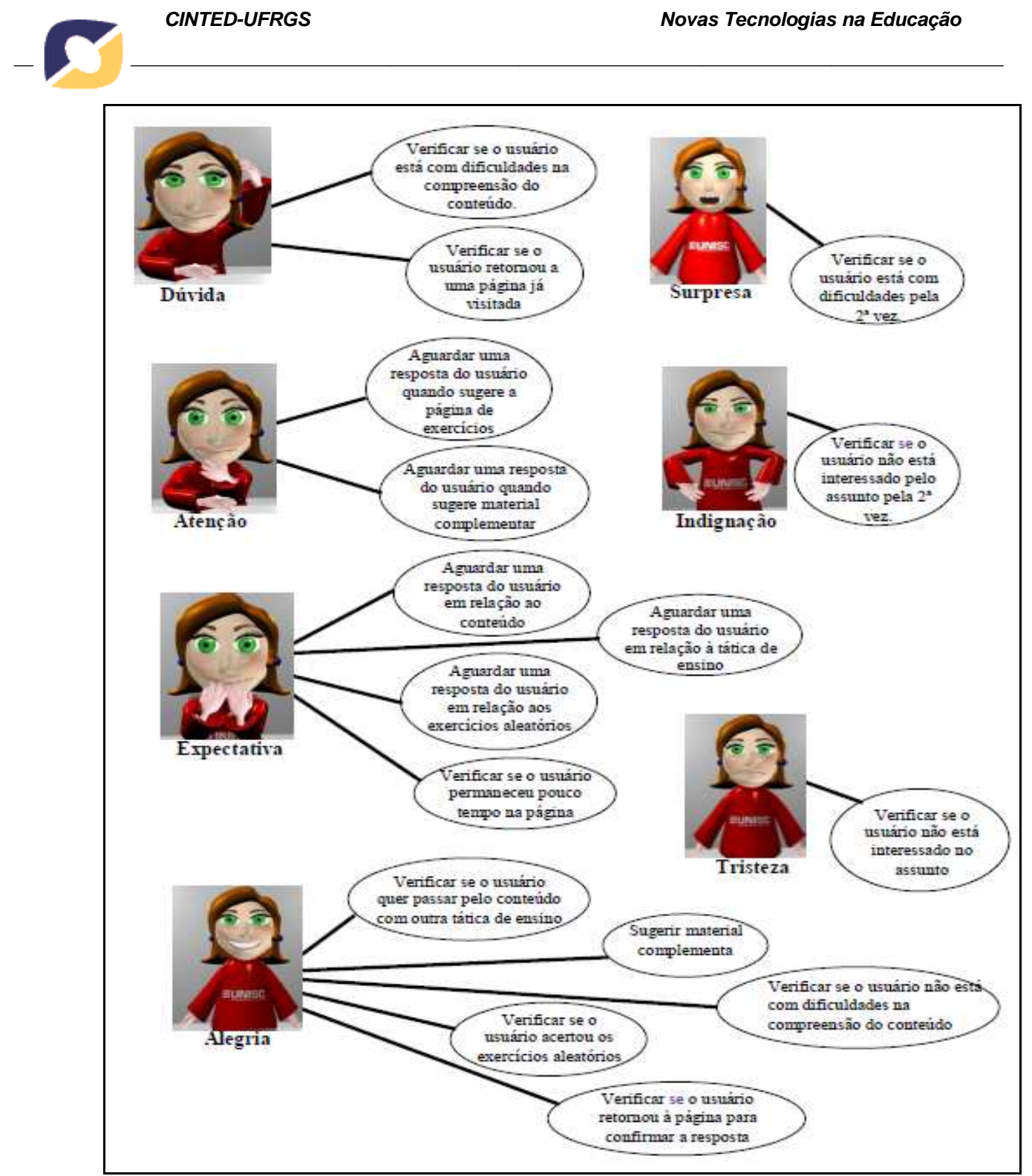

Figura 3 - Diagrama de casos de uso

O agente companheiro Dimi expressa as seguintes emoções: felicidade e tristeza. A tristeza é expressa quando o estudante tem dificuldades, ao errar um exercício ou quando este não está gostando da interação. Na figura 4 é apresentada a sequência do comportamento do agente frente à emoção de tristeza.

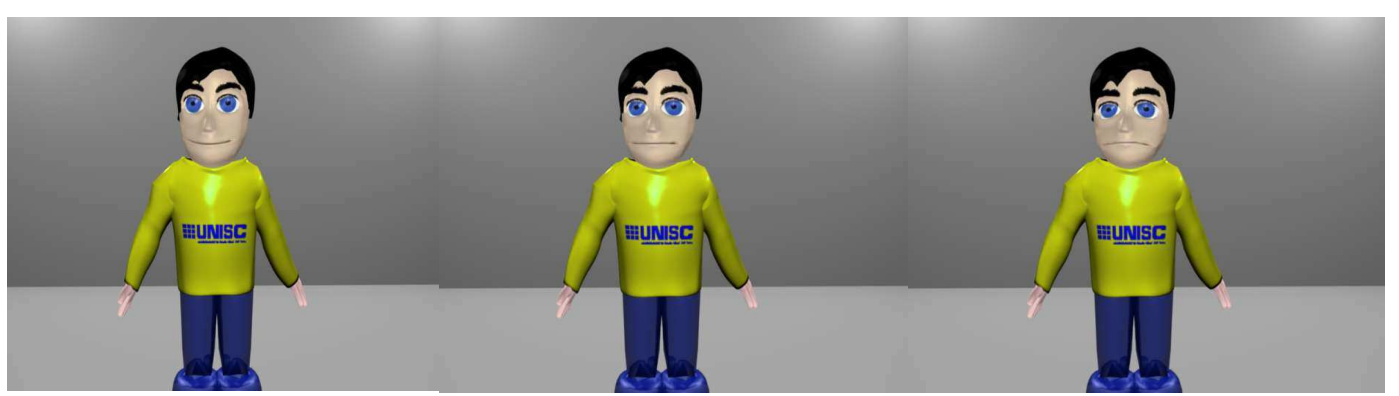

Figura 4 - Expressão de tristeza do Dimi no ambiente virtual de aprendizagem

A forma de expressão das emoções pelo agente companheiro ocorre através do comportamento observável, tais como: se o estudante pular uma página; se as respostas do estudante estão corretas quando estiver desenvolvendo os exercícios; se o estudante necessita de ajuda. 
As principais características do agente companheiro Dimi são: extrai informações do ambiente de ensino; aparece no início da interação sem a necessidade de solicitação; proporciona auxílio e incentivo na interação com o estudante.

O agente companheiro Dimi assume os papéis: colaborativo (ajudar o usuário em um exercício, por exemplo) e causador de problemas (incentivar o usuário a não fazer um exercício, por exemplo), que também pode ser uma característica típica de um colega em sala de aula.

Durante a interação do estudante com o ambiente virtual, o agente Dimi monitora quando este passa para a próxima página, questionando sobre um exercício do conteúdo em questão, conforme a figura 5.

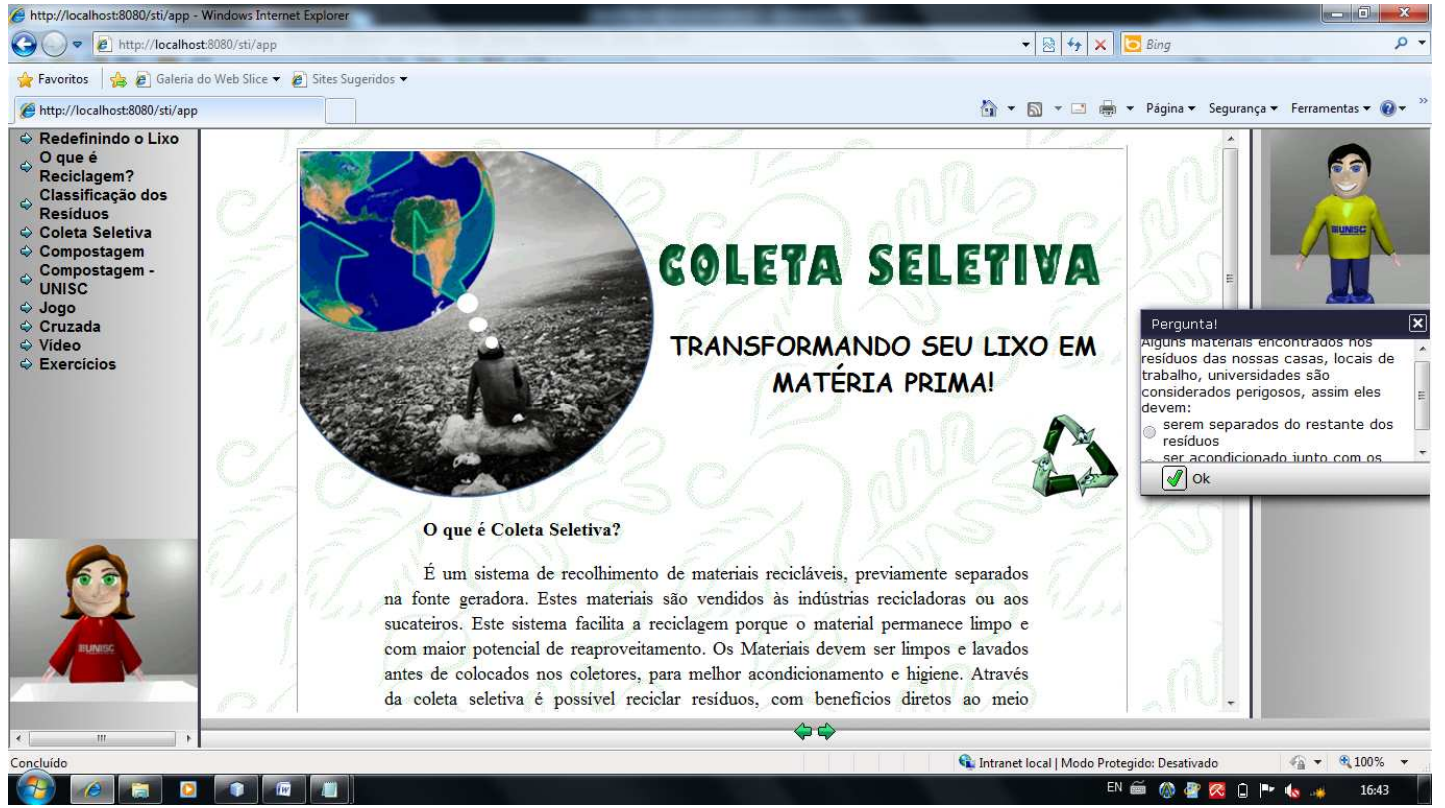

Figura 5 - Reação do agente Dimi quando o estudante avança uma página

Quando o estudante responde corretamente a questão, o agente expressa a emoção de felicidade, apresentando uma mensagem de incentivo e realizando um novo questionamento ao estudante por meio de outro exercício. Já, ao errar a questão, o agente emite uma mensagem de notificação e o incentiva à leitura de um material complementar, expressando tristeza.

\section{Conclusões}

Este projeto contribui no processo de ensino-aprendizagem, oferecendo um ambiente dinâmico de interação com os estudantes e motivando-os na realização de atividades propostas com o uso de agentes pedagógicos emocionais.

Por meio da computação afetiva o computador é capaz de reconhecer e transmitir as emoções, sendo que as melhores formas de captar as emoções são através das expressões faciais e do comportamento observável.

A utilização de ambientes virtuais de aprendizagem como prática pedagógica para o desenvolvimento cognitivo vem proporcionando atividades desafiadoras que oferecem maior motivação e entusiasmo nos processos de ensino-aprendizagem.

Essa pesquisa vem contribuindo em aspectos como: utilização de uma nova tecnologia de aprendizagem interativa, mediada por computador, uso de um sistema tutor inteligente que proporciona a interdisciplinaridade (já que se destina a diferentes áreas 
de atuação), adaptando-se ao estilo cognitivo do estudante, com o apoio dos agentes pedagógicos tutor e companheiro, cujos comportamentos são determinados por percepções advindas do ambiente de interação com o estudante; e disponibilização de um ambiente de ensino-aprendizagem dinâmico e eficiente.

A vantagem do uso de agentes pedagógicos emocionais está na busca de melhorias dos processos de interação com os estudantes. Um destaque foi a metodologia empregada para modelagem das emoções, com a integração de três fontes: o modelo OCC, a leitura do livro O Corpo Fala e as expressões faciais definidas por Ekmann.

Outro destaque é a ideia da atuação de um agente companheiro, que se identifica com as ações do estudante, como se fosse outro colega ou amigo, mas atuando em um ambiente com uma base de conhecimento bem estruturada; e um agente tutor, com a finalidade de guiar o estudante em um processo adequado de ensino-aprendizagem.

\section{Agradecimento}

Os autores expressam o seu reconhecimento ao Conselho Nacional de Desenvolvimento Científico e Tecnológico (CNPq) e à Universidade de Santa Cruz do Sul (UNISC) pelo auxílio financeiro no desenvolvimento deste trabalho.

\section{Referências}

BEHAR, P. A.; el al. Avaliação de Ambientes Virtuais de Aprendizagem: O Caso do ROODA na UFRGS. Revista Avances en Sistemas e Informática, v. 4, p. 81-100, Bogatá, 2007.

BERCH, M. Em direção a agentes pedagógicos com dimensões afetivas. Porto Alegre: UFRGS, 2001. Tese de Doutorado.

CHOU, C.; CHAN, T-W.; LIN, C. Redefining The Learning Companion: The Past, Present, And Future Of Educacional Agents. Computers \& Education, 255-269. 2003.

EKMANN, P. "Facial Expressions". Handbook of Cognition and Emotion. New York: John Wiley \& Sons Ltd. Chapter 16, 1999. Disponível em: http://www.paulekman.com. Acesso em 15 out. 2009.

GAVIDIA, J. J. Z.; ANDRADE, L. C. V. de. Sistemas Tutores Inteligentes. Jun 2003. Disponível em: <http://www.cos.ufrj.br/ ines/courses/cos740/leila/cos740/STImono.pdf>. Acesso em 20 mar. 2010.

JAQUES, P. A.; LEHMANN, M.; JAQUES, K. S. F. Avaliando a afetividade de um agente pedagógico animado emocional. Em Simpósio Brasileiro de Informática na Educação, 19. Fortaleza: SBIE, 2008.

KAMMPFF, A. J. C.; et. al. Relação entre o perfil do usuário e a escolha do perfil do tutor. Novas Tecnologias na Educação, UFRGS, v. 3, n. 1, mai 2005.

KENDALL, F. P.; CREARY, E. K. Músculos, provas e funções. Editora Manole, 1995.

LINO, N. L.; TEDESCO, P.; ROUSY, D. Modelo de Percepção de Agentes Inteligentes baseados em Emoções. 2006. Disponível em: http://www.cin.ufpe.br/ $\sim$ sbgames/proceedings/files/ModelodePercep.pdf. Acesso em 15 jan. 2010.

PICARD, R. Affective Computing. Cambridge: MIT Press, 1997.

AZEVEDO, B. F. T.; TAVARES, O. de L. Um Ambiente Inteligente para Aprendizagem Colaborativa. 2001. Disponível em: <http://www.brie.org/pub/index.php/sbie/article/viewFile/144/130>. Acesso em 20 mai. 2010.

ROSS, J. D.; ROSS, C. M. Teste Ross de Processos Cognitivos. Instituto Pieron de Psicologia Aplicada, 1976.

SILVA, J. M. C. da; HECK G. Utilizando o questionário MSLQ para identificação de estados afetivos em um ambiente virtual de aprendizagem. Itajaí, 2008. Disponível em: < http://www.inf.ufsc.br/ julia/pub/28.pdf>. Acesso em 10 abr. 2010.

TOMPAKOW, R. O corpo fala. 64ª edição. Petrópolis: Vozes, 2008. 